\title{
Painful nodule on umbilicus: Sister Mary Joseph nodule as an unusual but important manifestation of widespread gallbladder cancer
}

Hong Ja Kim and Ho Jin Yong

Department of Gastroenterology, Dankook University Hospital, Cheonan, Korea

Received: December 19, 2016 Revised : January 20, 2017 Accepted: January 31, 2017

\section{Correspondence to}

Hong Ja Kim, M.D.

Tel: +82-41-550-3917

Fax: +82-41-556-3256

E-mail: hjkimjung@hotmail.com
A 61-year-old woman presented to the hospital with a 2-month history of a tender nodule on the umbilicus and an 1-week history of icteric sclera. Her vital signs were within normal ranges. On physical examination, we noted an 1-cm sized, hard and painful nodule on the umbilicus without swelling (Fig. 1A). The laboratory test showed the following findings: hemoglobin $11.4 \mathrm{~g} / \mathrm{dL}$, aspartate aminotransferase $123 \mathrm{U} / \mathrm{L}$, alanine transaminase $74 \mathrm{U} / \mathrm{L}$, total bilirubin $12.98 \mathrm{mg} / \mathrm{dL}$, C-reactive protein $2.29 \mathrm{mg} / \mathrm{dL}$, and alkaline phosphatase 477 IU/L. Cancer antigen 19-9 level was 3,880 U/mL. Abdominopelvic computed tomography showed a $7.4 \times$ $5.9 \times 5.4 \mathrm{~cm}$ sized intrahepatic mass arising from the fundus of the gallbladder, multiple enlarged abdominal lymph nodes, enhancing seeding nod- ules in the peritoneum and focal umbilical thickening with enhancement (Fig. $1 \mathrm{~B}$ and ${ }_{1 \mathrm{C}}$ ). Ultrasound-guided needle aspiration cytologic examination of the intrahepatic mass confirmed the diagnosis of adenocarcinoma of the gallbladder (Fig. 2A). The result of skin biopsy of the umbilicus was compatible with metastatic adenocarcinoma (Fig. 2B and 2C). Her malignancy was judged to be inoperable due to the extent of the disease. A biliary stent was inserted to relieve jaundice. Palliative chemotherapy (cisplatin + gemcitabine) every 3 weeks was started.

Sister Mary Joseph nodule, an umbilical metastatic nodule, is reportedly present in $1 \%$ to $3 \%$ of all intra-abdominal and/or pelvic malignancies. The most common primary source is gastric carcinoma in men and ovari-
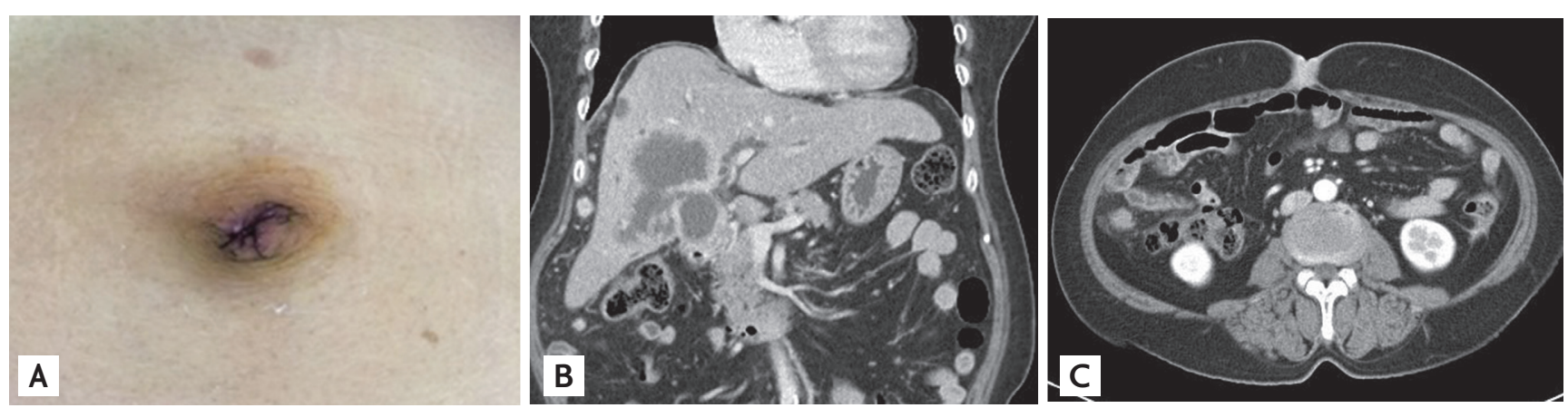

Figure 1. (A) A hard, tender, and slightly bulging erythematous nodule without discharge or surface ulceration within the umbilicus, (B) abdominopelvic computed tomography showing an intrahepatic mass originating from the gallbladder and peritoneal seeding nodules, (C) and focal umbilical thickening with enhancement. 

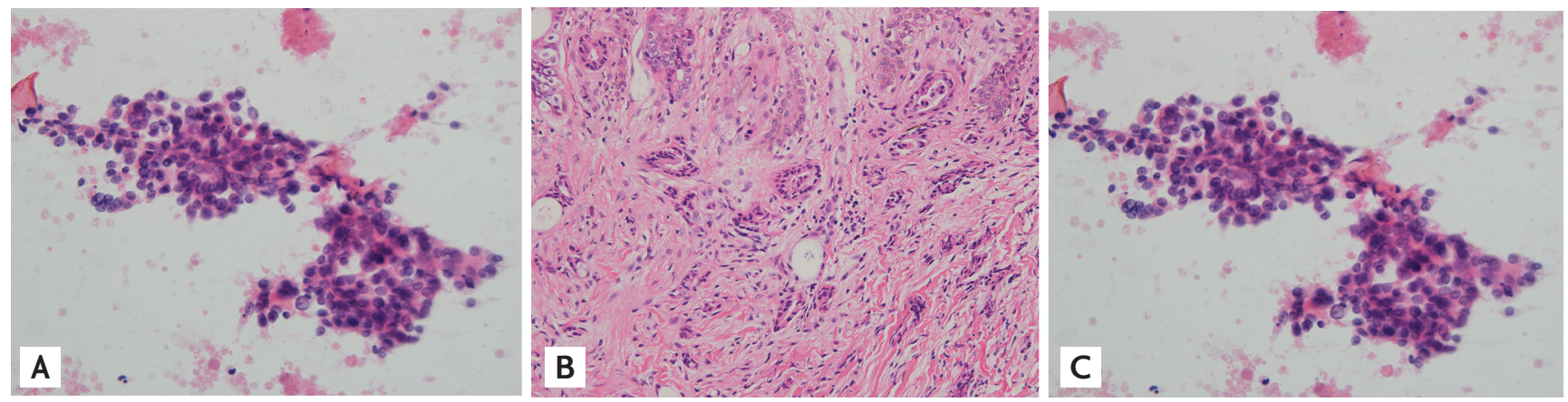

Figure 2. (A) Microphotograph shows adenocarcinoma cells in the liver $(\mathrm{H} \& \mathrm{E}, \times 400)$, (B) histopathology of the skin over the umbili$\mathrm{cal}$ area is compatible with infiltration of adenocarcinoma cells (H\&E, $\times 200)$, and $(\mathrm{C})$ cytokeratin 7 positivity $(\times 200)$.

an carcinoma in women. Although Sister Mary Joseph nodule is unusual in a cancerous condition, this case suggests that Sister Mary Joseph nodule can be a crucial initial manifestation of widespread gallbladder cancer, and therefore, careful physical examination is necessary.

\section{Conflict of interest}

No potential conflict of interest relevant to this article was reported. 